\title{
The Particularity of Chinese Translation of Chinese Literary Works in Chinese Literature--Take the English Translation of Mo Yan's Novel Life and Death are Wearing Me Out as an Example
}

\author{
Shi Yingjuan \\ School of Foreign Languages Jiangsu University, Jiangsuzhenjiang, 212013
}

Keywords: Mo Yan; The title; Translation; Chinese literature

\begin{abstract}
Under the guidance of the strategy of Chinese literature going out, translators always tend to use domestication strategy to translate Chinese literature works, which can improve the acceptance of western readers. However, after decades of efforts, especially after Mo Yan won the Nobel Prize in literature, Chinese culture, which was suppressed by western culture, will gain a certain international cultural "discourse power", making more people pay attention to Chinese literature. Therefore, in order to attract the attention of western readers, the translation of the titles of literary works is particularly important. At this point, a book with the mystique of eastern culture is more attractive than a great, healthy vernacular for easy acceptance. This paper will analyze from the perspective of times and readers that the title translation should not be the same as the full text translation, but should adopt the alienation strategy, and take the English translation of Mo Yan's "Life and Death are Wearing Me Out" as an example to illustrate the specific application of this strategy.
\end{abstract}

\section{Introduction}

With 5,000 years of history and culture, China has attracted worldwide attention. Nowadays, with more and more frequent cultural exchanges in the world, Chinese literature has been gradually translated into various languages and spread around the world. Translation plays a vital role in making Chinese literature go global. Take Mo Yan, the winner of the Nobel Prize in literature, for example. His success lies in his excellent writing skills, while ge haowen, who is known by the media as the "chief midwife of Mo Yan's works", has also contributed a lot.

\section{The naturalization strategy of Chinese literature going abroad}

\subsection{Domestication and alienation}

American translation theorist Laurence Venuti proposed two opposite translation concepts of domestication and foreignization in his 1995 book the invisible translator. The domestication strategy refers to that translators should follow the language and culture of the target language and approach the target language readers, adopt the language and cultural norms of the target language in terms of form and culture, so as to avoid cultural conflicts. When readers read the translated works, they feel that they are reading the original text of the target language. Alienation strategy refers to accepting the language and cultural differences of foreign language texts, choosing the translation corresponding to the expression of the source language, striving to preserve the language and cultural characteristics of the source language, so that readers can experience exotic customs, culture and history.

There has been a long debate in translation circles about whether domestication or alienation should be adopted in translation. According to Venuti, "the purpose of alienation translation is to develop a translation theory and practice that resists the dominance of the cultural values of the target language in order to show the differences in the language culture of the text". Chinese scholars teleconference held similar views ${ }^{[1]}$, "The alienation means that the translator can not only not restricted by the target language and text habits, but also at the right time, with smooth, opaque 
speech style, sedulous reservation on language culture, so as to give the readers with different reading experience". ${ }^{[2]}$ However, Andre Lefvere pointed out that translation is domestication. ${ }^{[3]}$ Qian Zhongshu is also inclined to the naturalization strategy of translation. He believes that "the highest standard of literary translation is' naturalization ', which means that the transformation of a work from one language to another can not show the hard and far-fetched traces due to the differences in language habits, but also can completely preserve the original flavor. ${ }^{[4]}$

\subsection{Application of domestication strategy}

In the process of translating Chinese works, cultural vacancy and the difference of thinking between China and the west are two major obstacles hindering the development of Chinese literature. However, in order to better realize the "Chinese cultural exit strategy", most scholars agree that translators should consciously adjust their translations according to the ideology, cultural system and social factors of the target language countries so as to better adapt to the target language system. A good translator should understand the publishing and accepting the truth in the context of western culture, so as to make the translation adapt to the foreign environment and find a living space in the heterogeneous culture. [5] At the present stage, we have to admit that Chinese literature is still on the edge of world literature, and western readers' understanding of Chinese literature and culture is still one-sided and backward, even biased. It is a gradual process to change the strong cultural psychology and the inherent literary concept of the west. Therefore, it is an inevitable process to create a system based on the acceptance of readers.

In The Writing Life published by The Washington post in 2002, Ge Haowen systematically elaborated his personal translation views. He believed that it was his favorite practice to present some expressions in Chinese in English without losing The meaning of Chinese, so as to make them more acceptable to western readers. In the translation of life and death fatigue, he tries to present the cultural load words to the readers in their original flavor, but he still adopts the domestication strategy for the overall grasp of the text. The translation is not word-for-word mechanical translation, but takes the text as the basic unit. After the content is sorted out, the creative translation is carried out to make the language more consistent with the habits of the target readers. According to the differences between Chinese and English language modes and writing norms, ge has adjusted the discourse mode, restructured the discourse, and avoided the common translation cavity. In terms of the macroscopic aspect of discourse, considering the influence of cultural context on readers' receptivity, ge haowen boldly deleted the part of discourse with cultural deficiency. In addition, the unnecessary details are also deleted, so that the plot is always centered on the main line of the story.

\section{The particularity of title translation}

\subsection{The alienation strategy of title translation}

The title is the essence of the work, a highly refined and concentrated summary of the work itself. It not only carries the main information of the works and reflects the overall features of the works, but also attracts the attention of the readers and achieves a good marketing effect. The translation of the title is in harmony with the content, and the two complement each other. A good title translation should, like the original text, arouse the expectation of reading before the opening of the book and the aftertaste of reading after the closing of the book. Therefore, the translation of the title should adopt the strategy of alienation.

The translation of the book title is a special intercultural communication. When dealing with cultural differences, translators should respect the characters and uniqueness of different cultures, so that readers can find the exotic cultural information and cultural images contained in the source text at a glance, so as to achieve the purpose of "cultural facsimile". The domesticating method will wipe out the national color of the source culture, making readers feel illusory and fail to find the special cultural concepts in the source culture. Therefore, at the level of full-text translation, we can try to adopt the domesticating strategy to reduce the readers' reading difficulty. The application of the foreignization strategy of title translation can satisfy readers' reading psychology of seeking for 
differences and let them understand the unique Chinese culture, leaving them a deep impression.

\subsection{Seize the opportunity of The Times}

China has more and more cooperation and exchanges with other countries, and Chinese culture has become more and more influential in the world, which has attracted more foreigners to learn Chinese culture and Chinese literature, promoting the translation and communication of literary works. It has added weight to Chinese literature that Mo Yan won Nobel Prize. The New York times reported that Mo was one of the publishers' three favorite writers over the past decade. Compared with other awards, the Nobel literature prize is easier to win, because those who know language can read and interpret themselves. Because literature is written in the language of a country, it is easier to associate with a nation, its language, thoughts and culture. The Nobel literature prize can get the largest number of people in a country involved, and can be related to the national emotion to a certain extent. As Chinese literature is rooted in the target language literature system, we should timely make a moderate turn in the text selection strategy, select to translate literature text with relatively profound language, complicated content and abundant Chinese literature and culture image, supplement and perfect Chinese literature image in the target language step by step, and then achieve the "going out" of Chinese literature. Therefore, the use of the alienation strategy of the title translation can be regarded as an important step to "go out".

\subsection{Get to know your audience}

At present, the bounded literary readers is the general trend of social diversification, and the readers get what they need from the cultural products provided by the market. Therefore, those who love Chinese literature are mostly pure literature readers, in which teenagers are less than people above middle age. Literature lovers and literary creators are the core of reading. The cultural circle of each reader forms corresponding cultural psychological structure, which is actually "cultural accumulation" and is affected by "latent culture" factors such as race, class and education background. The cultural education and aesthetic edification of a reader with a high cultural psychological structure are obviously richer and more perfect, with higher aesthetic expectations. Strong aesthetic expectations prompt readers to have a "dialogue" with various literary texts. Without certain aesthetic expectations, readers will read such books as modern family rather than literary works.

In the context of literature entering the market, whether works sell well or not is directly related to the survival of writers, publications and publishing houses, which also means that in the process of literary production, readers' reception psychology and aesthetic expectations should be fully considered. The title with Oriental mystique is more appealing to readers who love Chinese culture and want to know it. Readers won't be deterred by the title, but will see the reading process as a challenge to figure out doubts. Therefore, title of Chinese literary works can be translated in a bold and original way.

\section{Translation of title of Fatigue of Life and Death, Mo Yan's work}

Mo Yan once indicated that the title of Fatigue of Life and Death was from Buddhist classics. Mo intended to quote the Buddhist term on the title page: "Life, death and fatigue are from greed. Less desire, more freedom. "Life and death" sounds rich Buddhist taste while it's literally translated by Ge Haowen as "Life and Death Are Wearing Me Out." This translation is unsatisfactory and superficial and means to consider English readers' reception psychology.

First of all, in the endless cycle of living and dying embodied in the profound novel, people and animals are constantly experience fatigue of life and death, which seems to be an endless and bitter cycle, difficult to escape. However, reincarnation shows the eternity of life and equality of all, which even makes you to say "life and death is the only thing not to fatigue". While there is a difference between Ge Haowen's understanding and the original title's wise meaning. Therefore, the original title is translated literally with inconsistent forms and the spiritual connotation compared to the original work. Secondly, the expression of the complex social and historical events covered by 
the vast time span, costs lots of Mo's energy, can be attributed to human desire. However, Ge Haowen's translation completely fails to reflect the spiritual core of the original work.

Life and death Fatigue can be translated into Reincarnation Fatigue, which means reborn successively into another form. It is quite strange to western readers, but exactly matches with the spiritual connotation of the original work, and the length and rhythm of the translation are close to the original title. When readers see reincarnation, they first think of "Buddhism, reincarnation", which is totally different from the "original sin" and fighting bravely for atonement emphasized by Christianity, the mainstream religion in the west. Reincarnation and fatigue seem to be a paradoxical combination. "Reincarnation" should be of positive optimism. How comes the fatigue? Such a translation should arouse the reader's thinking and interest in reading.

\section{Conclusion}

In the publishing and distribution of translated cultural works, the titles containing rich national cultural information have a very important influence on the market acceptance. From unknown works to recognized classics, the translation and dissemination of Mo Yan's novels leave us lots of reflections. Chinese literature should promote the "going global" strategy, learning from spreading process of Mo Yan's novels in the English-speaking world, seize the translation opportunity, know the readers' expectations and demands, and open channels for "marginal literature" to move towards the central system.

\section{References}

[1] Venuti, L. The Translator's Invisibility: A History of Translation [M]. London: Routledge, 1995.121-125.

[2] Wang Dongfeng. Domestication and alienation: confrontation between spear and shield [J]. Chinese Translators Journal, 2002(9): 24-26.

[3] Lefvere, A. Translation, Rewriting \& the Manipulation of Literary Fame[M]. London: Routledge, 1992.67-78.

[4] Qian Zhongshu. Lin Shu's translation[C]. Beijing: the Commercial Press, 1981.36-45.

[5] Wang Qiwei. Translation mechanism and strategy of "Chinese literature goes out" [J]. Publishing Research, 2014(8):89-92. 